\title{
Activated Macrophage-Mediated Endogenous Prostaglandin and Nitric Oxide-Dependent Relaxation of Lymphatic Smooth Muscles
}

\author{
Haijie WANG \\ The 1st Department of Physiology, Shinshu University School of Medicine, Matsumoto, 390 Japan
}

\begin{abstract}
The effects of macrophages activated by bacterial lipopolysaccharides (LPS) on the mechanical activity of lymph vessels with or without the endothelium were investigated using conventional bioassay preparations. Rat peritoneal macrophages emigrated by an injection of thioglycollate were isolated and cultured for $12 \mathrm{~h}$ in RPMI 1640 medium containing $10 \mu \mathrm{g} / \mathrm{ml}$ LPS. More than $97 \%$ of the cultured cells were stained with monoclonal antibody ED1 and demonstrated phagocytosis of acetylated low-density lipoprotein. The supernatant of the macrophages $(M \phi)$ suppressed significantly the basal tone of the lymphatic bioassay rings precontracted by $10^{-8} \mathrm{M}$ U46619. The $M \phi$-induced vasodilation of the lymph vessels was significantly reduced by $12 \mathrm{~h}$ preincubation of the macrophages with $5 \times 10^{-5} \mathrm{M}$
\end{abstract}

$\mathrm{N}^{\omega}$-nitro-L-arginine methyl ester (L-NAME), $10^{-5} \mathrm{M}$ indomethacin, $10^{-6} \mathrm{M}$ dexamethasone, or $10^{-5} \mathrm{M}$ cycloheximide. Simultaneous preincubation of $L$ NAME and indomethacin caused a synergistic reduction of the $M \phi$-induced vasodilation of the lymphatic bioassay rings. The superfusion of Krebs-bicarbonate solution containing $5 \times 10^{-5} \mathrm{M}$ L-NAME, $5 \times 10^{-5} \mathrm{M}$ aspirin, or the culture medium with no macrophages caused no significant effect on the $M \phi$-induced vasodilation. These findings suggest that macrophages activated by bacterial LPS produce a marked relaxation of lymphatic smooth muscles through the co-release of nitric oxide and vasodilative prostaglandins, which may result in the facilitation of edema formation in wound tissues. [Japanese Journal of Physiology, 47, 93-100, 1997]

Key words: rat peritoneal macrophage, nitric oxide, vasodilative prostaglandins, relaxation, lymph vessel.

The circulatory and migratory properties of white blood cells have evolved to allow the efficient surveillance of tissues for infectious pathogens and rapid accumulation at sites of injury and infection. Lymphocytes continually patrol the body for foreign antigens by recirculating from blood, through tissue, into lymph vessels. They percolate through draining lymph nodes in the lymphatic system and finally enter the thoracic duct, through which they return to the blood stream [1]. On the other hand, monocytes are far less numerous in the blood than lymphocytes, and their half-life is about $24 \mathrm{~h} \mathrm{[2].} \mathrm{They} \mathrm{are} \mathrm{phagocytic} \mathrm{and}$ also accumulate in response to traumatic injury or bacterial infection. Thus, they migrate to sites where $\mathrm{T}$ lymphocytes have recognized antigens, as in de- layed-type hypersensitivity reactions [3]. After extravasation, they may differentiate through exudate or inflammatory macrophages into long-lived tissue macrophages or mononuclear phagocytes. After migrating into tissue, a part of the exudate or inflammatory macrophages find their way into lymph vessels $[1,3]$.

A number of studies have now established that macrophages, as endothelial cells $[4,5]$, synthesize nitric oxide (NO), and citrulline from L-arginine $[6,7]$. This arginine-dependent production of NO has been implicated in mediating the cytotoxic actions of the activated macrophages against a variety of target cells, including tumor cells [8]. Several studies have also demonstrated that endotoxin stimulates the induction 
of inducible cyclooxygenase (COX-2) in macrophages [9-11].

However, little information exists regarding the potential influence of activated macrophages on the mechanical activity of lymph vessels. Thus, this study was conducted using a conventional bioassay preparation, similar to arteries and veins, to evaluate whether or not activated macrophages produce a marked vasodilation of lymphatic smooth muscles. The second goal of this study was to test the hypothesis that macrophages stimulated by bacterial lipopolysaccharides (LPS) may co-release vasodilative prostaglandins (PGs) and NO, and then result in vasodilation in in vitro experiments.

\section{MATERIALS AND METHODS}

Macrophage isolation. Peritoneal macrophages were obtained from male Sprague-Dawley rats, 6-8 week old $(250-300 \mathrm{~g}), 4 \mathrm{~d}$ after intraperitoneal injection of $10 \mathrm{ml} 4 \%$ thioglycollate medium (Sigma, St. Louis, USA). After $4 \mathrm{~d}$, the rats were sacrificed by decapitation, and the peritoneal cells were obtained by washing the peritoneal cavity with cold $\left(4^{\circ} \mathrm{C}\right)$ Hank's balanced salt solution (HBSS, Sankyo Pure Chemicals, Tokyo, Japan). Cell counts were performed using a hemocytometer.

The peritoneal cells $\left(5 \times 10^{6} \mathrm{cells} / \mathrm{dish}\right)$ were allowed to adhere to $20-\mathrm{mm}$ culture dishes for $2 \mathrm{~h}$ $\left(37^{\circ} \mathrm{C}, 5 \% \mathrm{CO}_{2}\right.$ and $95 \%$ air) in RPMI 1640 medium (Sankyo Pure Chemicals) containing $10 \%$ fetal calf serum (Nalgene, Victoria, Australia) and antibiotics $(100 \mu \mathrm{g} / \mathrm{ml}$ streptomycin and $100 \mathrm{units} / \mathrm{ml}$ penicillin $\mathrm{G})$. The nonadherent cells were removed by washing two times with calcium- and magnesium-free cold $\left(4^{\circ} \mathrm{C}\right) \mathrm{HBSS}$. The adherent cells were scraped carefully with a thin silicon rubber and centrifuged at $1,000 \mathrm{rpm}$ for $10 \mathrm{~min}$ to collect the macrophages. The cells were resuspended at a cell density of $5 \times 10^{6} \mathrm{cells} /$ dish, and then incubated for $12 \mathrm{~h}$ in humidified $5 \%$ $\mathrm{CO}_{2}$ and $95 \%$ air at $37^{\circ} \mathrm{C}$ in RPMI 1640 medium containing $10 \mu \mathrm{g} / \mathrm{ml}$ bacterial LPS with or without various agents. The cell preparation was more than $98 \%$ viable as assayed by trypan blue (Sigma) exclusion, and consisted of more than $98.1 \%$ macrophages as judged by Wright and nonspecific esterase (Muto Chemicals, Tokyo, Japan) staining or the phagocytosis of acetylated low-density lipoproteins labeled with 1,1'-diocta-decyl-3,3,3'3'-tetramethyl-indocarbocyanine perchlorate (Dil-Ac-LDL; Biomedical Technologies Inc., Stoughton, USA). After culturing, the macrophages were washed three times with $37^{\circ} \mathrm{C}$ HBSS. Then, the fresh medium containing bacterial
LPS with or without the agents was added to the dishes and incubated for $30 \mathrm{~min}$. Then, $1 \mathrm{ml}$ of supernatant of the macrophages was removed from the dish and perfused over $1 \mathrm{~min}$ through bioassay preparations.

Immunocytochemistry. The cultured macrophages were air-dried and fixed in a mixture of acetone and formalin $(40: 1)$ for $10 \mathrm{~min}$. Slides were washed three times in phosphate-buffered saline (PBS). After washing in PBS, the slides were covered with a 1:10 dilution of FITC-labeled mouse anti-rat monoclonal antibody ED1 (mAb ED1, Serotec, Oxford, UK) for $30 \mathrm{~min}$. After washing again with PBS, the slides were mounted in a glycerol-PBS $(9: 1)$ solution and examined using fluorescence microscopy. Control slides were incubated in the same way, omitting the response with $\mathrm{mAb}$ ED1.

Bioassay preparation. Experiments were performed using thoracic ducts taken from mongrel dogs of either sex, anesthetized with pentobarbital sodium $(25 \mathrm{mg} / \mathrm{kg}$, I.V.). The lymph vessels were maintained in cold $\left(4^{\circ} \mathrm{C}\right)$ Krebs-bicarbonate solution of the following millimolar composition: $120.0 \mathrm{NaCl}, 5.9 \mathrm{KCl}$, $25.0 \mathrm{NaHCO}_{3}, 1.2 \mathrm{NaH}_{2} \mathrm{PO}_{4}, 2.5 \mathrm{CaCl}_{2}, 1.2 \mathrm{MgCl}_{2}$, and 5.5 glucose. After the adherent loose connective and adipose tissues of the vessel were removed, cylindrical rings ( $7 \mathrm{~mm}$ in length) were cut from the isolated dog thoracic ducts. Care was taken not to damage the endothelial cells. Some arterial rings were everted, and the exposed endothelial cells were mechanically removed by rubbing the internal surface with Krebs-soaked filter paper (Tokyo Advantec, Tokyo, Japan). The presence or absence of endothelial cells was confirmed histologically by silver staining [12]. The complete denudation of endothelial cells was also proven functionally by an experimental finding that no acetylcholine-induced NO-mediated relaxation was observed in the lymphatic preparations without the endothelium. The lymphatic ring with or without the endothelium was suspended directly in an organ bath by means of two thin silk strings passed through its lumen. One string was connected to an isometric force transducer (Shinko Tsushin, Tokyo, Japan). The other string was anchored at the bottom. The circumferential isometric tension detected by the transducer was amplified and recorded on a directwriting oscillograph (NEC Sanei, Tokyo, Japan). The resting tension of the lymphatic bioassay ring was set and maintained at $0.5 \mathrm{~g}$, being found to be optimal for obtaining the maximal contractile response to a highpotassium $\left(80 \mathrm{mM} \mathrm{K} \mathrm{K}^{+}\right)$Krebs-bicarborate solution. The high-potassium solution was prepared by replacing part of the $\mathrm{NaCl}$ in normal Krebs solution with 
equimolar amounts of $\mathrm{KCl}$. The lymphatic bioassay ring was superfused at a constant rate $(3.5 \mathrm{ml} / \mathrm{min})$ in $37^{\circ} \mathrm{C}$, pH 7.4 Krebs-bicarbonate solution. Superfusion of the solution containing $10^{-8} \mathrm{M} U 46619$, a thromboxane $\mathrm{A}_{2}$ analogue, produced a tonic contraction of the bioassay rings, being $60-70 \%$ of the contraction induced by $80 \mathrm{mM} \mathrm{K}^{+}$in each ring. After the U46619induced contraction had reached a steady state, the macrophage supernatant stimulated by bacterial LPS with or without dexamethasone, cycloheximide, $\mathrm{N}^{\omega_{-}}$ nitro-L-arginine methyl ester (L-NAME), L-NAME + $\mathrm{L}$-arginine, or indomethacin was superfused $(1 \mathrm{ml} /$ $\mathrm{min}$ ) through the lymphatic bioassay rings simultaneously with $3.5 \mathrm{ml} / \mathrm{min}$ Krebs-bicarbonate solution containing $10^{-8} \mathrm{M}$ U46619. After the end of each series of experiments, Krebs-bicarbonate solution containing U46619 $\left(10^{-8} \mathrm{M}\right)$ and sodium nitroprusside (SNP, $10^{-7} \mathrm{M}$ ) was superfused directly over the lymphatic bioassay ring to obtain maximum relaxation.

The same experiment protocol as mentioned above was also conducted with some lymphatic bioassay rings superfused with Krebs-bicarbonate solution containing $10^{-8} \mathrm{M}$ U46619 and L-NAME or aspirin.

Drugs. The following agents were used: aspirin, L-NAME, L-arginine, dexamethasone, cycloheximide, U46619, bacterial LPS, and thioglycollate medium (Sigma), acetylcholine chloride (Daiichi Seiyaku, Tokyo, Japan), and SNP (Merck, Darmstadt, Germany). All concentrations, except for LPS and thioglycollate medium, are expressed as a molar concentration of the solution superfusing the bioassay rings.

Statistical analysis. Each experimental group consisted of at least four culture dishes of macrophages and lymph vessels taken from different rats and dogs, respectively. Experimental values in the text and figures were expressed as mean \pm standard error of mean (SEM) with $n$ indicating the number of experiments. Statistical analyses were made using either Dunnet's test after one-way analysis of variance (ANOVA) or Student's $t$-test for unpaired or paired observations. Differences were considered to be statistically significant when $p<0.05$.

\section{RESULTS}

\section{ED1 antigen localization}

Figure 1 shows representative microphotographs of the immunocytochemical examination of mAb ED1 expression of the thioglycollate-induced rat peritoneal cells. Most cells (more than $97.0 \%$ of 600 cells, $n=4$ ) were stained with $\mathrm{mAb}$ ED1 (Fig. 1A), showing a granular cytoplasmic staining pattern (Fig. 1B). No staining of the surface cell membrane was observed
(Fig. 1B).

\section{Macrophage supernatant-induced vasodila- tion of lymph vessels}

Figure 2 shows representative tracings that the supernatant of macrophages $(\mathrm{M} \phi)$ caused a significant reduction in the precontraction of the lymphatic bioassay ring with or without the endothelium. The application of $1 \mathrm{ml}$ supernatant for $1 \mathrm{~min}$ produced a prompt reduction of the U46619-induced precontraction of the lymphatic smooth muscles, which returned to the control level about $5 \mathrm{~min}$ after starting superfusion. The reduction of tension in the lymphatic ring with or without the endothelium was approximately $70 \%$ of the SNP-induced maximum relaxation.

In control experiments, an increase in the flow rate ( 3.5 to $5 \mathrm{ml} / \mathrm{min}$ ) of Krebs-bicarbonate solution perfused through the lymphatic bioassay rings, or the application of HBSS used to wash the macrophages $(1 \mathrm{ml} / \mathrm{min})$ produced no significant effect on the precontraction level of the bioassay rings.

\section{Effects of L-NAME and/or indomethacin on macrophage supernatant-induced vasodila- tion of lymph vessels}

The $M \phi$-induced vasodilation of the lymph vessels was significantly reduced by preincubation of the macrophages with $5 \times 10^{-5} \mathrm{M}$ L-NAME (Fig. 3; with endothelium, $61.8 \pm 2.4 \%, n=8$, in the control vs $27.2 \pm 1.7 \%, n=8$, with L-NAME, $p<0.05$; without endothelium, $65.7 \pm 3.3 \%, n=8$, in the control vs $30.2 \pm 2.6 \%, n=8$, with L-NAME, $p<0.05$ ).

The preincubation of macrophages with $10^{-5} \mathrm{M}$ indomethacin also caused a significant reduction in the $M \phi$-induced relaxations of the lymphatic bioassay rings with or without the endothelium (Fig. 3; with endothelium, $39.3 \pm 1.0 \%, n=8$, with indomethacin, $p<0.05$ vs control; without endothelium, $42.6 \pm 2.3 \%$, $n=8$, with indomethacin, $p<0.05$ vs control).

In the pretreatment with both $5 \times 10^{-5} \mathrm{M}$ L-NAME and $10^{-5} \mathrm{M}$ indomethacin, the supernatant of macrophages produced a smaller relaxation of the lymph vessel rings than that obtained under single inhibition of NO synthase (NOS) or cyclooxygenase (Fig. 3; with endothelium, $10.5 \pm 2.1 \%, n=8$, blocking both enzymes, $p<0.01$ vs control; without endothelium, $10.0 \pm 1.5 \%, n=8$, blocking both enzymes, $p<0.01$ vs control).

\section{Effects of L-NAME and/or L-arginine on macrophages supernatant-induced vasodila- tion of lymph vessels}

The L-NAME-induced inhibition of the vasodila- 

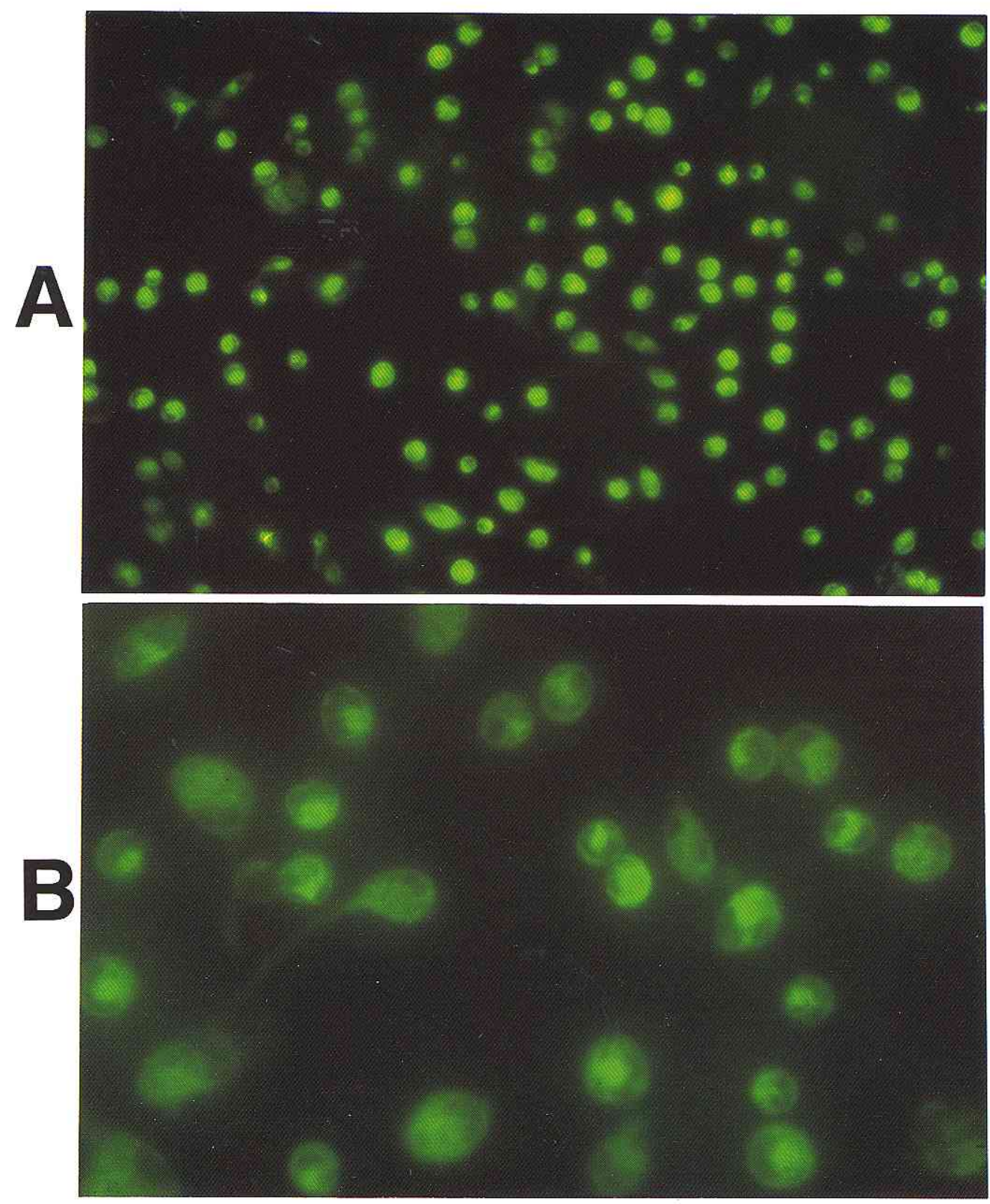

Fig. 1. Representative microphotographs of the immunocytochemical expression of $\mathrm{mAb}$ ED1 in thioglycollate-induced rat peritoneal cells. Magnification: A: $\times 200$; $\mathbf{B}: \times 600$

tions was significantly reversed by simultaneous treatment with $10^{-4} \mathrm{M}$ L-arginine (Fig. 4: with endothelium, $63.0 \pm 1.3 \%, n=8$, in the control; $32.2 \pm 1.9 \%$, $n=8$, with L-NAME vs $49.7 \pm 1.5 \%, n=8$, with LNAME and L-arginine, $p<0.05$ : without endothelium, $66.3 \pm 1.5 \%, n=8$, in the control; $34.7 \pm 2.3 \%, n=8$, with L-NAME vs $47.1 \pm 2.6 \%, n=8$, with L-NAME and L-arginine, $p<0.05$ ).

\section{Effects of dexamethasone or cycloheximide on macrophage supernatant-induced vasodi- lation of lymph vessels}

The preincubation of macrophages with $10^{-6} \mathrm{M}$ dexamethasone caused significant inhibition of the $M \phi$-induced relaxation in the lymphatic bioassay rings with or without endothelium. The summarized data for dexamethasone are shown in Fig. 5 (with endothelium, $62.0 \pm 2.8 \%, n=8$, in the control vs $8.9 \pm$ $0.9 \%, n=8$, with dexamethasone, $p<0.01$; without endothelium, $65.2 \pm 1.4 \%, n=8$, in the control vs $7.9 \pm$ $1.1 \%, n=8$, with dexamethasone, $p<0.01)$.

Preincubation with $10^{-5} \mathrm{M}$ cycloheximide also significantly reduced the $\mathrm{M} \phi$-induced relaxation of the lymphatic bioassay rings with or without the endothelium (Fig, 6; with endothelium, 61.8 $\pm 1.7 \%, n=8$, in the control vs $13.9 \pm 1.9 \%, n=8$, with cycloheximide, $p<0.01$; without endothelium, $66.2 \pm 2.7 \%, n=8$, in the control vs $11.8 \pm 1.3 \%, n=8$, with cycloheximide, $p<0.01$ ). 


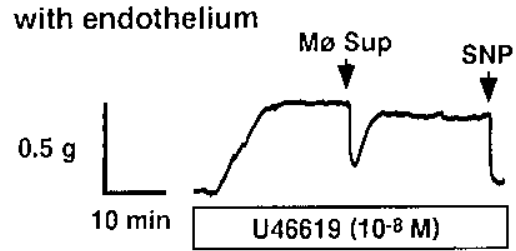

without endothelium

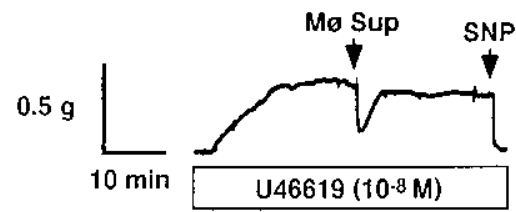

Fig. 2. Representative recordings of macrophage supernatant-induced relaxation of the precontracted $\left(10^{-8} \mathrm{M}\right.$ U46619) lymphatic bioassay ring with (upper panel) or without (lower panel) endothelium. Mф Sup, macrophage supernatant; SNP, $10^{-7} \mathrm{M}$ sodium nitroprusside.

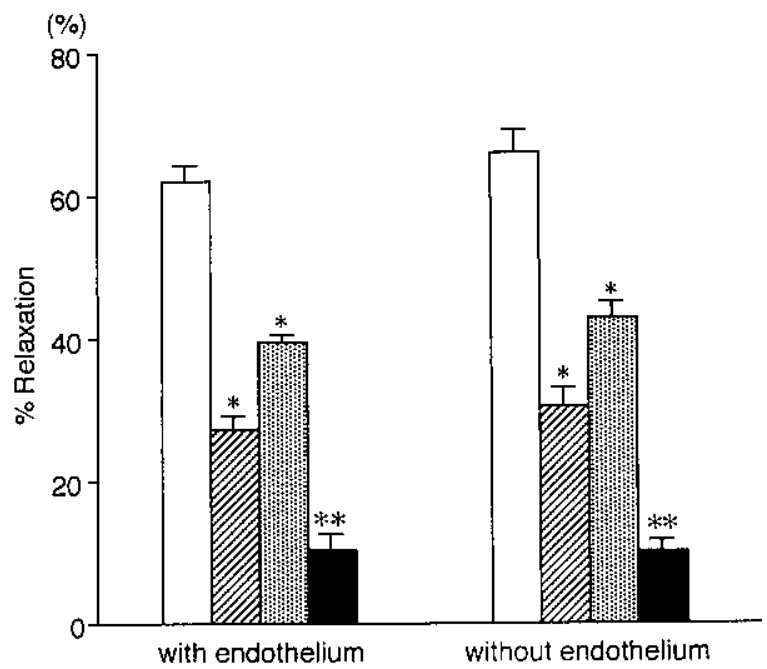

Fig. 3. The macrophage supernatant-induced vasodilation of the lymphatic bioassay rings with (left columns) or without endothelium (right columns) in the presence or absence of preincubation with $5 \times 10^{-5} \mathrm{M} \mathrm{L}$ NAME (hatched columns) and (solid columns) /or (dotted columns) $10^{-5} \mathrm{~m}$ indomethacin. Open columns denote the control. The ordinate shows the extent of relaxation as a percentage of $10^{-7} \mathrm{M}$ SNP-induced relaxation in each ring. ${ }^{*} p<0.05,{ }^{* *} p<0.01$ vs control.

\section{Effects of superfused L-NAME or aspirin on the macrophage supernatant-induced vasodi- lation of lymph vessels.}

The superfusion of Krebs-bicarbonate solution containing $5 \times 10^{-5} \mathrm{M}$ L-NAME or $5 \times 10^{-5} \mathrm{M}$ aspirin caused no significant effect on the $M \phi$-induced vasodilations of the lymphatic bioassay rings with or without the endothelium (Fig. 7; with endothelium, $67.1 \pm 1.4 \%, n=8$, in the control, $66.4 \pm 2.1 \%, n=8$, perfusion of L-NAME, $65.2 \pm 2.4 \%, n=8$, perfusion of

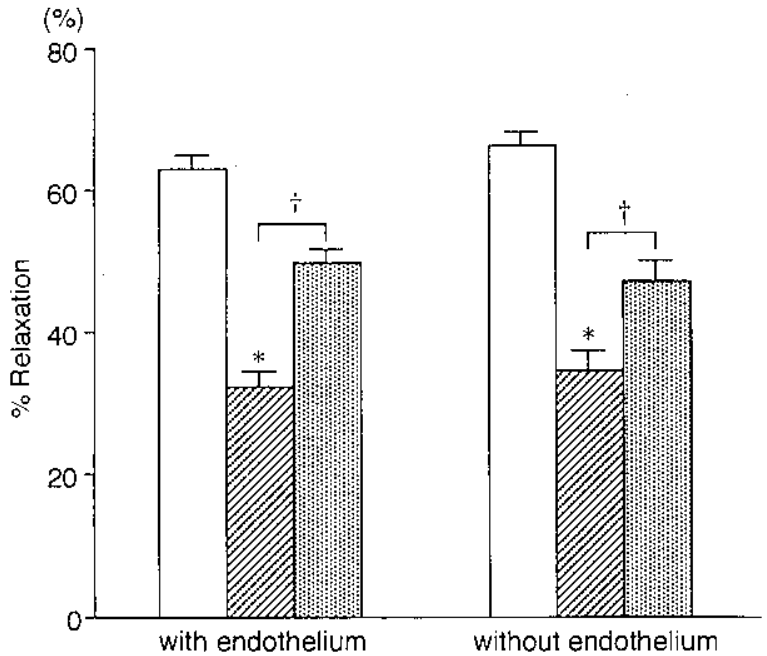

Fig. 4. The macrophage supernatant-induced vasodilation of the lymphatic bioassay rings with (left columns) or without (right columns) endothelium in the presence or absence of preincubation with $5 \times 10^{-5} \mathrm{M} \mathrm{L}$ NAME (hatched columns) and/or $10^{-4} \mathrm{M}$ L-arginine (dotted columns). Open columns denote the control. The ordinate shows the same term as that in Fig. $3 .{ }^{*} p<0.05$ vs control, ${ }^{\dagger} p<0.05$ vs L-NAME.

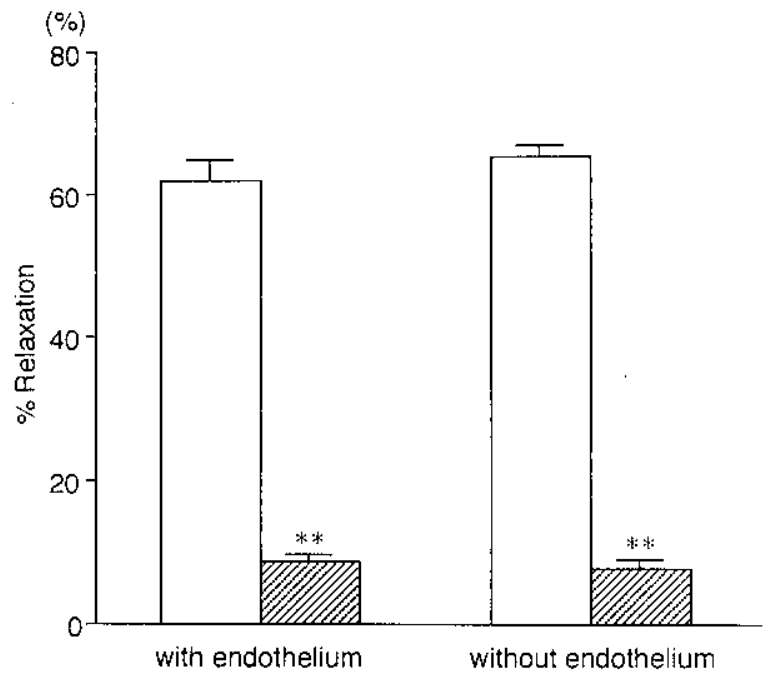

Fig. 5. The macrophage supernatant-induced vasodilation of the lymphatic bioassay rings with (left columns) or without endothelium (right columns) in the presence or absence of preincubation with $10^{-6} \mathrm{M}$ dexamethasone. Open columns show the control. The ordinate shows the same item as that in Fig. $3 .{ }^{* \star} p<0.01$ vs control.

aspirin; without endothelium, $68.9 \pm 1.2 \%, n=8$, in the control, $66.1 \pm 1.8 \%, n=8$, perfusion of L-NAME, $67.1 \pm 1.1 \%, n=8$, perfusion of aspirin). The culture medium containing no macrophages $(1 \mathrm{ml} / \mathrm{min})$ produced no significant relaxation of the precontracted lymph vessels with or without the endothelium (Fig. 7). 


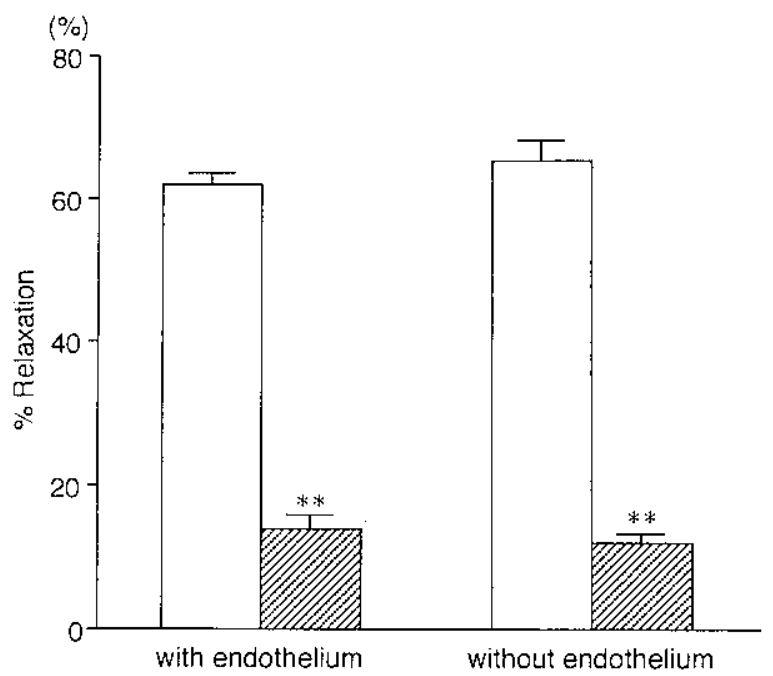

Fig. 6. The macrophage supernatant-induced vasodilation of the lymphatic bioassay rings with (left columns) or without (right columns) endothelium in the presence or absence of preincubation with $10^{-5} \mathrm{M}$ cycloheximide. Open columns show the control. The ordinate shows the same item as that in Fig. $3 .{ }^{* *} p<0.01$ vs control.

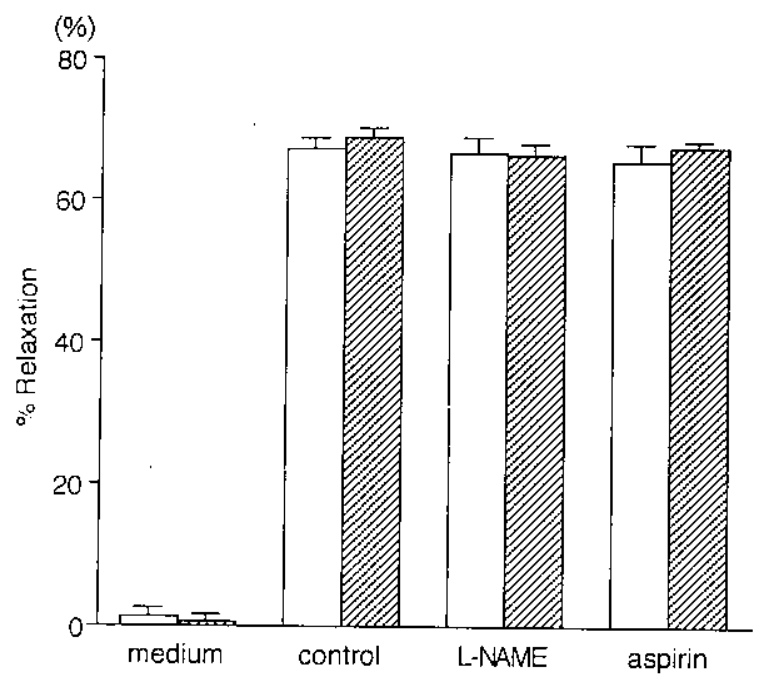

Fig. 7. The macrophage supernatant-induced vasodilation of the lymphatic bioassay rings with (open columns) or without endothelium (hatched columns) which were superfused with Krebs-bicarbonate solution containing culture medium without macrophages, $5 \times$ $10^{-5} \mathrm{M}$ L-NAME, or $5 \times 10^{-5} \mathrm{M}$ aspirin. The ordinate shows the same item as that in Fig. 3.

\section{DISCUSSION}

\section{Activated macrophages cause vasodilation} of lymphatic smooth muscles. This study clearly demonstrates that peritoneal macrophages stimulated by bacterial LPS cause a marked relaxation of lymphatic smooth muscles, which may inhibit lymph transport in vivo, and result in the facilitation of edema formation in tissues. The general function of the lymphatic system is to return fluid and protein which escapes from blood capillaries to the circulation. The mechanisms by which these functions are carried out depend on active and passive driving forces, as well as upon the rate of lymph production in organs and tissues. The passive driving mechanisms are due to the compression and suction of lymph vessels resulting from extrinsic activities such as the muscle pump [13], the respiratory pump [14], and arterial pulsation [15]. In dog thoracic duct, which contains a few smooth muscle layers in the wall [16], passive driving forces such as oscillatory changes in intrathoracic pressure are believed to be the main mechanism of lymph transport in the thoracic duct. In the lymph vessel, lymphatic smooth muscle tone seems to play a major role in the regulation of compliance of the wall, thereby affecting passive driving forces.

In the experiment reported here, the collected cells consisted of more than $98.1 \%$ macrophages as judged not only by esterase staining and the phagocytosis of Dil-Ac-LDL but also by the expression of mAb ED1. In addition, more than $97 \%$ of the cells revealed $\mathrm{mAb}$ ED1 with only a granular cytoplasmic staining pattern. These findings suggest strongly that the cells are extravasated monocytes, and neither lymphocytes nor resident macrophages in the peritoneal cavity [17].

The emigrated monocytes called exudate or inflammatory macrophages play an important role in the regulation of acquired and innate immunity [18], in part, by the secretion of cytokines including interleukin 1 (IL-1), tumor necrosis factor $\alpha$ (TNF- $\alpha$ ), and interferon $\gamma$ (IFN- $\gamma$ ). After migrating into tissue, the macrophages find their way into lymph vessels and finally enter draining lymph nodes in the lymphatic system. From the evidence [18], it is reasonable to expect that the inflammatory macrophages extravasated into the interstitial fluid of wounds and then migrated into the lymphatic system may play important pathophysiological roles in the regulation of myogenic activity of lymph vessels and result in the modulation of lymph transport mechanisms. However, further investigation will be needed to evaluate, in detail, the critical role of activated macrophages in edema formation in in vivo experiments.

Activated macrophages co-release NO and vasodilative PGs. Macrophages activated by bacterial LPS or cytokines have the ability of coinducing two key enzymes, inducible NO synthase (iNOS), and inducible cyclooxygenase (COX-2), which may result in regulating their functions [19].

An important aspect of this study is the clear demonstration that activated macrophages co-released NO and vasodilative PGs, resulting in a marked relax- 
ation of lymphatic smooth muscles. Pretreatment with $10^{-5} \mathrm{M}$ indomethacin, at a concentration known to inhibit cyclooxygenase in the tissues [20], caused a significant reduction of $M \phi$-induced relaxation in the lymphatic bioassay rings. This finding suggests that vasodilative PGs play an important role in $M \phi$-induced vasodilation.

Furthermore, L-NAME, an inhibitor of NO biosynthesis [21], significantly suppressed the $\mathrm{M} \phi$-induced relaxation of lymphatic smooth muscles. The simultaneous treatment with L-arginine, a physiological precursor for NO synthesis [21], caused a significant reversal of L-NAME-induced inhibition of vasodilation. These findings strongly suggest that $M \phi$-induced vasodilation is also mediated by the release of NO or its related compounds from macrophages.

The co-release of NO and vasodilative PGs from macrophages was also confirmed by the experimental finding that simultaneous treatment with both indomethacin and L-NAME produced a synergistic reduction of $M \phi$-induced vasodilation of the lymphatic bioassay rings. The conclusion may be compatible with the findings that $M \phi$-induced vasodilation was significantly reduced by pretreatment with glucocorticoids such as dexamethasone or cycloheximide, an inhibitor of protein synthesis in cells. These findings are in agreement with several studies that dexamethasone or cycloheximide inhibit significantly the induction of iNOS and COX-2 in macrophages $[22,23]$. It is well known that $\mathrm{NO}$ and vasodilative PGs are co-released from vascular endothelial cells by the stimulation of vasoactive agents [20] or shear stress [24], and then produce a relaxation of vascular smooth muscles.

However, about $10 \%$ of the $M \phi$-induced vasodilation remained even though the macrophages were pretreated with both indomethacin and L-NAME, dexamethasone, or cycloheximide. The cytokines such as IL-1, TNF- $\alpha$, IFN- $\gamma$, or oxygen radicals, which were released during the activation of macrophages by bacterial LPS, may have contributed, in part, to the remaining $M \phi$-induced vasodilation. This possibility is compatible with several studies that cytokines, such as TNF- $\alpha$ inhibit the contractility of isolated arteries [25].

The author thanks Professor Toshio Ohhashi of Shinshu University School of Medicine for his encouragement and financial support for completing studies and preparing the manuscript.

\section{REFERENCES}

1. Springer TA: Traffic signals on endothelium for lymphocyte recirculation and leukocyte emigration. Annu Rev

\section{Physiol 57: 827-872, 1995}

2. Issekutz AC and lssekutz TB: Quantitation and kinetics of blood monocyte migration to acute inflammatory reactions, and $\mathrm{IL}-1 \alpha, \mathrm{TNF}-\alpha$, and IFN- $\gamma$. J Immunol 151: 2105-2115, 1993

3. Ziegler-Heitbrock HW: The biology of the monocyte system. Eur J Cell Biol 49: 1-12, 1989

4. Palmer RMJ, Ferrige AG, and Moncada S: Nitric oxide release accounts for the biological activity of endothelium-derived relaxing factor. Nature 327: 524-526, 1987

5. Palmer RMJ, Ashton DS, and Moncada S: Vascular endothelial cells synthesize nitric oxide from L-arginine. Nature: 664-666, 1988

6. Hibbs JB Jr, Taintor RR, Varrin Z, and Rachlin EM: Nitric oxide: a cytotoxic activated macrophage effector molecule. Biochem Biophys Res Commun 157: 87-94, 1988

7. Marletta MA, Yoon PS, Lyenger R, Leaf CD, and Wishnok JS: Macrophage oxidation of L-arginine to nitrite and nitrate: nitric oxide is an intermediate. Biochemistry 27: 8706-8711, 1988

8. Stuehr DJ and Nathan CF: Nitric oxide: a macrophage product responsible for cytostasis and respiratory inhibition in tumor target cells. J Exp Med 169: 1543-1555, 1989

9. Akarasereenont P, Mitchell JA, Bakhle YS, Thiemerman $C$, and Vane JR: Comparison of the induction of cyclooxygenase and nitric oxide synthase by endotoxin in endothelial cells and macrophages. Eur $\mathrm{J}$ Pharmacol 273: 121-128, 1995

10. Fu JY, Masferrer JL, Seibert K, Racz A, and Needbman $P$ : The induction and suppression of prostaglandin $\mathrm{H}_{2}$ synthase (cyclooxygenase) in human monocytes. J Biol Chem 265: 16737-16740, 1990

11. Humes JL, Bonney RJ, Pelus L, Dahlgren ME, Sandowski SJ, Kuehl FA Jr, and Davies P: Macrophages synthesize and release prostaglandins in response to inflammatory stimuli. Nature 269: 149-150, 1977

12. Poole JCF, Sanders AG, and Florey HW: The regeneration of aortic endothelium. J Pathol Bacteriol 75: 133143,1958

13. McMaster PD: Changes in the cutaneous lymphatics of human beings and in the lymph flow under normal pathological conditions. J Exp Med 65: 347-372, 1937

14. Morris $B$ : The effect of diaphragmatic movement on the absorption of protein and of red cells from the peritoneal cavity. Aust J Exp Biol Med 31: 239-246, 1953

15. Webb RC and Starzl TE: The effect of blood vessel pulsations on lymph pressure in large lymphatics. Bull Johns Hopkins Hosp 93: 401-407, 1953

16. Ohhashi T, Azuma T, and Sakaguchi M: Functional and structural characteristics of canine thoracic duct. J Jpn Coll Angiol 22: 109-116, 1982 (in Japanese)

17. Damoiseaux JGMC, Dopp EA, Calame W, Chao D, MacPherson GG, and Dijkstra CD: Rat macrophage lysosomal membrane antigen recognized by monoclonal antibody ED1. Immunology 83: 140-147, 1994

18. Allison AC: Mechanisms by which activated macrophages inhibit lymphocytes responses. Immunol Rev 40: 1-27, 1978

19. Granger DL, Hibbs JB Jr, Perfect JR, and Durack DT: 


\section{H. WANG}

Metabolic rate of L-arginine in relation to microbiostatic capability of murine macrophages. J Clin Invest 85: 264-273, 1989

20. Kawai $Y$ and Ohhashi T: Prostaglandin $\mathrm{F}_{2 \alpha}$-induced endothelium-dependent relaxation in isolated monkey cerebral arteries. Am J Physiol 260: H1538-H1543, 1991

21. Palmer RMJ, Rees DD, Asthton DS, and Moncada S: LArginine is the physiological precursor for the formation of nitric oxide in endothelium-dependent relaxation. Biochem Biophys Res Commun 153: 1251-1256, 1988

22. DiRosa $M$, Radomski $M$, Carnuccio $R$, and Moncada S:
Glucocorticoids inhibit the induction of nitric oxide synthase in macrophages. Biochem Biophys Res Commun 172: $1246-1252,1990$

23. Moncada S, Palmer RMJ, and Higgs EA: Nitric oxide: physiology, pathophysiology and pharmacology. Pharmacol Rev 43: 109-142, 1991

24. Koller A, Sun D, Huang A, and Kaley G: Corelease of nitric oxide and prostaglandins mediates flow-dependent rat gracilis muscle arterioles. Am J Physiol 267: H326-H332, 1994

25. Aoki N, Siegfried M, and Lefer AM: Anti-EDRF effect of tumor necrosis factor in isolated, perfused cat carotid arteries. Am J Physiol 256: H1509-H1512, 1989 